\title{
Nota Científica \\ Determinação do comprimento ótimo de transectos para estimativa de necromassa florestal
}

\author{
Denise Jeton Cardoso ${ }^{1}$, Alexander Christian Vibrans ${ }^{2}$, Alba Valéria Rezende ${ }^{3}$, Frans Corneel Pareyn ${ }^{4}$, Joberto Veloso Freitas ${ }^{5}$, \\ Maria Augusta Doetzer Rosot ${ }^{1}$, Yeda Maria Malheiros de Oliveira ${ }^{1}$ \\ ${ }^{1}$ Embrapa Florestas, Estrada da Ribeira, km 111, CP 319, CEP 83411-000, Colombo, PR, Brasil \\ ${ }^{2}$ Fundação Universidade Regional de Blumenau, Centro de Ciencias Tecnológicas, Departamento de Engenharia Florestal, Rua São Paulo, 3250 , Itoupava Seca \\ CEP 89030000, Blumenau, SC, Brasil \\ ${ }^{3}$ Universidade de Brasília Campus Universitário Darcy Ribeiro, Asa Norte, CP 04357, CEP 70910-900, Brasilia, DF, Brasil \\ ${ }^{4}$ Associação Plantas do Nordeste, Rua Dr. Nina Rodrigues, 265, Iputinga, CEP 50731-280, Recife, PE, Brasil \\ ${ }^{5}$ Serviço Florestal Brasileiro - SCEN, Av. L4 N, Trecho 2, Bloco H, CEP 70818-900, Brasília, DF, Brasil
}

"Autor correspondente:

denise.cardoso@embrapa.br

Termos para indexação:

Biomassa caída

Médodo do intercepto

Amostragem

Index terms:

Deadwood

Line intercept method

Sampling

Histórico do artigo:

Recebido em 04/05/2012

Aprovado em 01/07/2013

Publicado em 30/09/2013

doi: 10.4336/2013.pfb.33.75.391
Resumo - O objetivo deste trabalho foi avaliar diferentes comprimentos de transecto para determinação da necromassa florestal caída sobre o chão. Os dados são provenientes de transectos de 10 metros, medidos durante o teste de metodologia do Inventário Florestal Nacional na Amazônia, Cerrado e Caatinga, e no inventário em Santa Catarina, representando Floresta Ombrófila Mista e Floresta Estacional Decidual. O comparativo do coeficiente de variação, para transectos de 10 a $150 \mathrm{~m}$ indica que as maiores alterações desse estimador ocorrem no intervalo de 10 até 50 $\mathrm{m}$, estabilizando-se a partir deste comprimento. A adoção de transectos de $10 \mathrm{~m}$ nas tipologias avaliadas é recomendável, pois com este comprimento ocorre uma redução de $35 \%$ na distância total de caminhamento em relação aos transectos de $20 \mathrm{~m}$, para obter o mesmo erro amostral.

\section{Determining the optimal length of transects for estimating coarse woody debris}

\begin{abstract}
The objective of this paper was to evaluate different transect lengths for determination of coarse woody debris on the ground. The data came from 10-meter-long transects, measured during the National Forest Inventory methodology test in the Amazon, Cerrado and Caatinga, and the forest inventory in Santa Catarina State, representing Araucaria Forest and Deciduous Forest. The comparison among the coefficient of variation obtained for transects from 10 to $150 \mathrm{~m}$ long indicates that the greatest changes in this estimator occur in the interval from 10 up to $50 \mathrm{~m}$, stabilizing from this length. The adoption of $10 \mathrm{~m}$ transects in the typologies evaluated is recommended, because with this length there is a $35 \%$ reduction in total walking distance in relation to the $20 \mathrm{~m}$ transects to obtain the same sampling error.
\end{abstract}


O termo necromassa refere-se ao material lenhoso que pode ser encontrado sobre o chão das florestas, incluindo toras, gravetos, galhos, fragmentos de madeira, bem como árvores mortas em pé (Woldendorp et al., 2004). Apesar de ser um componente significante dos ecossistemas florestais, representando cerca de $10 \%$ a $20 \%$ da biomassa total acima do solo, sua quantificação é geralmente ignorada em muitos inventários florestais que visam a avaliação de estoque de carbono (Brown, 2002).

A quantificação da necromassa caída sobre o chão da floresta requer uma metodologia que facilite a medição e que seja eficiente, principalmente em locais de cobertura vegetal densa. A amostragem por transectos ou linhas de intercepto é considerada apropriada para este fim. No entanto, ainda são poucas as referências de sua aplicação no Brasil, tais como as de Cruz Filho \& Silva (2009), Galvão Filho (2010), Barbosa et al. (2009) e Baker \& Chao (2001). Em países como Suíça (Böhl \& Brändli, 2007), Estados Unidos (USDA Forest Service, 2011) e Canadá (Canadian Forest Inventory Committee, 2008), este método vem sendo aplicado amplamente em Inventários Florestais Nacionais e, na Austrália (Mckenzie, 2000), faz parte do Sistema Nacional de Levantamento de Carbono, para estimativa de carbono de necromassa.

No método de transectos, a linha amostral é de fato, um plano vertical, onde são medidos os diâmetros dos fragmentos de madeira que ocorreram em interseção ao plano e é classificado o seu nível de degradação.

O procedimento de amostragem consiste no caminhamento ao longo da linha de inventário, medindose o diâmetro de cada tora ou fragmento no ponto de intersecção com a linha e registrando o comprimento total das linhas de inventário. A equação básica para a estimativa do volume é dada por (Van Wagner, 1968):

$$
V=\left(\frac{\pi^{2}}{8 \times L}\right) \times \sum_{i=1}^{n} d^{2}
$$

Em que: $V=$ volume para o transecto, por unidade de área; $\mathrm{d}=$ diâmetro de um fragmento de necromassa; $\mathrm{L}=$ comprimento do transecto; $\mathrm{n}=$ número de fragmentos ou toras encontrados no transecto.

Quando o volume dos fragmentos é dado em m3.ha-1, o comprimento do transecto (L), em metros e o diâmetro do fragmento (d) em centímetros, a fórmula (Van Wagner, 1982) se torna:

$$
V=\left(\frac{1,234}{L}\right) \times \sum_{i=1}^{n} d^{2}
$$

Pesq. flor. bras., Colombo, v. 33, n. 75, p. 317-325, jul./set. 2013
Nos casos em que os fragmentos não estão dispostos horizontalmente, a estimativa do volume é adaptada para:

$$
V=\left(\frac{1,234}{L}\right) \times \sum_{i=1}^{n}\left(d^{2} \times a\right)
$$

Em que: a = secante do ângulo de inclinação com a horizontal de cada fragmento amostrado.

Uma das decisões importantes para tornar este método viável está relacionada ao comprimento do transecto, o qual depende da quantidade e da variabilidade da necromassa no interior da área a ser inventariada.

Woldendorp et al. (2004), em um estudo em três tipos de florestas australianas, observaram que a variabilidade do volume de necromassa é relativamente alta e, portanto, estimativas com coeficiente de variação inferior a 50\% requerem intensidade amostral também alta. Para esses autores, a precisão da estimativa do volume aumentou com o aumento do comprimento do transecto. Um único transecto longo resultou em um coeficiente de variação menor que vários transectos menores, mas o custo efetivo foi maior. Esses mesmos autores não observaram aumento de precisão com a mudança no arranjo dos transectos em formato de L, triângulo ou quadrado.

Böhl \& Brändli (2007) observaram que o uso de transectos de comprimento superior a 30 m não ocasiona uma redução drástica no erro padrão da estimativa e recomendaram um comprimento de $20 \mathrm{~m}$ a $30 \mathrm{~m}$ por parcela para as condições do inventário nacional da Suíça.

No inventário nacional de Angola (Branthomme, 2009) adotou-se transectos com $20 \mathrm{~m}$ de comprimento, sendo estabelecidos três transectos em cada parcela do inventário, enquanto no Canadá, a amostragem considerou dois transectos de $30 \mathrm{~m}$ em cada parcela (Canadian Forest Inventory Committee, 2008); nos EUA, foi adotado o comprimento de 7,31 m ou 24 pés para cada transecto (USDA Forest Service, 2011).

No Brasil, a quantificação da necromassa depositada sobre o chão da floresta é uma das informações a ser obtida do Inventário Florestal Nacional (Serviço Florestal Brasileiro, 2012), como parte da informação necessária para o inventário de carbono. Porém, existe a necessidade de avaliar a variabilidade da ocorrência e das dimensões dos fragmentos de necromassa e definir se o comprimento adotado é realmente adequado. 
Para tanto, foi proposto o uso da amostragem por transectos de $10 \mathrm{~m}$ de comprimento, sendo dois em cada unidade de amostra. Em todo o território nacional, cada unidade de amostra será representada por um conglomerado em forma de cruz de malta (Péllico Netto \& Brena, 1997), com distância de 50 m entre as subunidades do conglomerado. Foram utilizados os dados dos transectos de $10 \mathrm{~m}$ medidos no Inventário Florestal Nacional em Santa Catarina, executado pela Fundação Universidade Regional de Blumenau - FURB, (Vibrans et al., 2010), que representam as formações vegetais de Floresta Ombrófila Mista e Floresta Estacional Decidual. Também foram utilizados os dados dos transectos de $10 \mathrm{~m}$ medidos nos demais biomas (Caatinga, Cerrado e Floresta Ombrófila Densa da Amazônia) durante os testes de metodologia de implantação do Inventário Florestal Nacional, executados pelo Serviço Florestal Brasileiro e Embrapa Florestas. Nos transectos medidos em Santa Catarina foi considerado diâmetro mínimo de $1 \mathrm{~cm}$ ou circunferência de $3 \mathrm{~cm}$, na Caatinga foi considerado todo o material com circunferência de, no mínimo, $2,5 \mathrm{~cm}$ e, nos demais locais analisados foi considerado diâmetro igual ou superior a $2,5 \mathrm{~cm}$.

Em todos esses conjuntos de dados, procedeu-se à simulação de comprimentos de transecto com a junção dos transectos até o comprimento máximo possível de ser obtido em cada situação (Tabela 1), desconsiderando-se o fato de que foram medidos em conglomerados distantes uns dos outros. Para efeito da análise, assumiu-se que a heterogeneidade do volume de necromassa era a mesma, tanto em transectos contínuos longos quanto em transectos curtos e distantes. Para confirmar esta hipótese, procedeuse também a medição de transectos dispostos de maneira contínua ao longo das quatro subparcelas de um conglomerado instalado na área da Embrapa Florestas, em Colombo, Paraná. Neste local, foram medidos quatro transectos de $50 \mathrm{~m}$ de comprimento, subdivididos a cada $10 \mathrm{~m}$, de maneira a possibilitar a análise de transectos com 10,20,30, 40 e $50 \mathrm{~m}$ de comprimento (Figura 1).

A avaliação dos diferentes comprimentos de transecto consistiu na análise gráfica do coeficiente de variação em função do comprimento do transecto. Esse indicador denota a variabilidade de volume de necromassa entre as unidades amostrais (transectos) em relação aos comprimentos testados. O coeficiente de variação é dado por:

$$
C V=\frac{s}{x} \times 100
$$

Também foi simulada a intensidade amostral necessária em cada tipologia para cada comprimento de transecto, para atingir erro amostral de $10 \%$ e de $15 \%$ :

$$
n=\left(\frac{s \cdot t \cdot 100}{E \cdot \bar{x}}\right)^{2}
$$

Em que: $\mathrm{n}=$ número de parcelas necessárias; $\mathrm{E}=$ erro percentual limite desejado $(\%) ; \mathrm{s}=$ desvio padrão; $\overline{\mathrm{X}}=$ média de volume dos transectos $\left(\mathrm{m}^{3} \mathrm{ha}^{-1}\right) ; \mathrm{t}=$ valor de $\mathrm{t}$ de student para um nível de confiança de $95 \%$.

Em um processamento preliminar, observou-se que o coeficiente de variação em volume de necromassa apresentou valores muito altos, devido à ocorrência esparsa de árvores ou galhos com diâmetro maior que $20 \mathrm{~cm}$, que foram observados em poucos transectos e somente nos conjuntos de dados do estado de Santa Catarina. A simulação do aumento do comprimento do transecto não demonstrou redução do coeficiente de variação em volume para estes conjuntos de dados, optando-se, assim, por desconsiderar na análise estatística o material com diâmetro superior a $20 \mathrm{~cm}$.

Transectos de $10 \mathrm{~m}$ de comprimento geraram resultados de coeficiente de variação entre 95,5\% no Cerrado e $141,7 \%$ na Caatinga. A simulação do comprimento de $20 \mathrm{~m}$ fez reduzir o coeficiente de variação, que assumiu valores entre $69,9 \%$ no Cerrado e $130 \%$ na Caatinga.

A redução mais acentuada do coeficiente de variação ocorreu do comprimento de $10 \mathrm{~m}$ até $50 \mathrm{~m}$, na Caatinga de $141,7 \%$ para $87,6 \%$, na Floresta Ombrófila Mista do Planalto Catarinense de $113,1 \%$ para $64,5 \%$ e na Floresta Estacional Decidual, em transição com Floresta Ombrófila Mista do oeste catarinense, de $117,0 \%$ para $56,6 \%$. Esta redução ocorreu também no conglomerado da Embrapa Florestas em Floresta Ombrófila Mista, com os transectos dispostos de maneira contínua, onde o coeficiente de variação diminuiu de $118,3 \%$ para $53,8 \%$. Em comprimentos de $50 \mathrm{~m}$ até $150 \mathrm{~m}$, a redução do coeficiente de variação foi menor, havendo uma tendência de homogeneidade (Figura 2). A forte oscilação dos valores de coeficiente de variação verificada para a Caatinga é devida à existência de parcelas sem ocorrência de toras ou fragmentos, em alguns trechos de transecto testados. 
Tabela 1. Número de transectos analisados nas diferentes situações.

\begin{tabular}{|c|c|c|c|c|c|c|c|}
\hline \multicolumn{2}{|l|}{ Bioma } & \multirow{2}{*}{$\begin{array}{c}\begin{array}{c}\text { Floresta } \\
\text { Ombrófila } \\
\text { Mista/ } \\
\text { Planalto } \\
\text { Catarinense }\end{array} \\
162\end{array}$} & \multirow{2}{*}{$\begin{array}{c}\text { Floresta Ombrófila } \\
\text { Mista - oeste } \\
\text { catarinense / } \\
\text { Floresta Estac. } \\
\text { Decidual }\end{array}$} & \multirow{2}{*}{$\begin{array}{c}\text { Caatinga } \\
26\end{array}$} & \multirow{2}{*}{$\begin{array}{c}\text { Cerrado } \\
8\end{array}$} & \multirow[t]{2}{*}{ Amazônia } & \multirow{2}{*}{$\begin{array}{c}\text { Floresta } \\
\text { Ombrófila } \\
\text { Mista / } \\
\text { Embrapa } \\
\text { Florestas } \\
20\end{array}$} \\
\hline \multirow{15}{*}{$\begin{array}{l}\text { Comprimento } \\
\text { do transecto } \\
\text { (m) }\end{array}$} & 10 & & & & & & \\
\hline & 20 & 81 & 132 & 13 & 4 & 6 & 12 \\
\hline & 30 & 54 & 88 & 9 & 3 & & 8 \\
\hline & 40 & 41 & 66 & 7 & & 3 & 8 \\
\hline & 50 & 33 & 52 & 6 & & & 4 \\
\hline & 60 & 27 & 44 & 5 & & & \\
\hline & 70 & 24 & 38 & 4 & & & \\
\hline & 80 & 21 & 33 & 5 & & & \\
\hline & 90 & 18 & 30 & 3 & & & \\
\hline & 100 & 17 & 27 & & & & \\
\hline & 110 & 15 & 24 & & & & \\
\hline & 120 & 14 & 22 & & & & \\
\hline & 130 & 13 & 21 & & & & \\
\hline & 140 & 12 & 19 & & & & \\
\hline & 150 & 11 & 18 & & & & \\
\hline
\end{tabular}

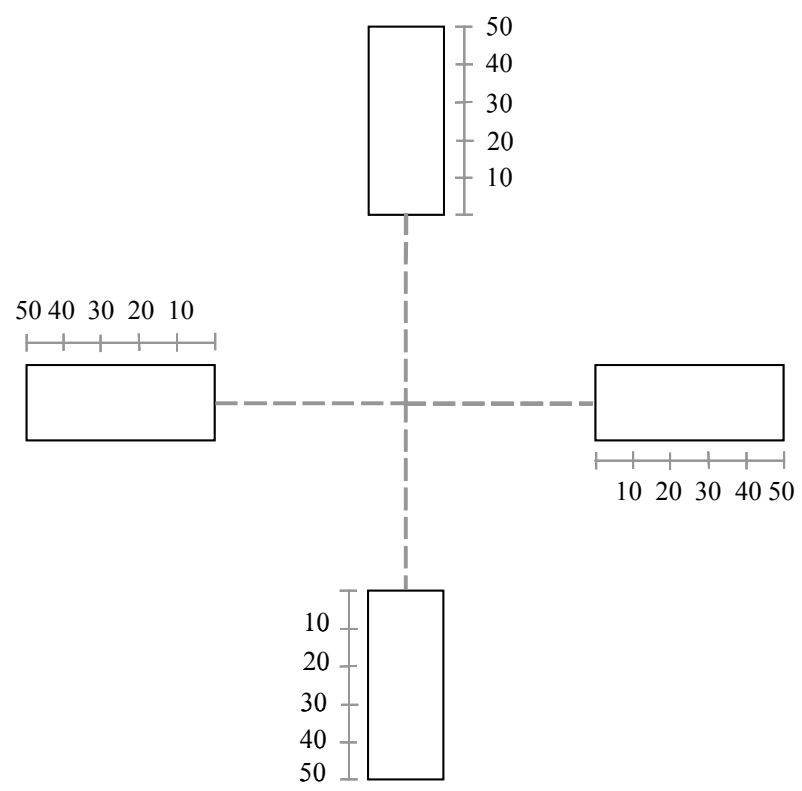

Figura 1. Distribuição dos transectos no conglomerado instalado na área da Embrapa Florestas. 


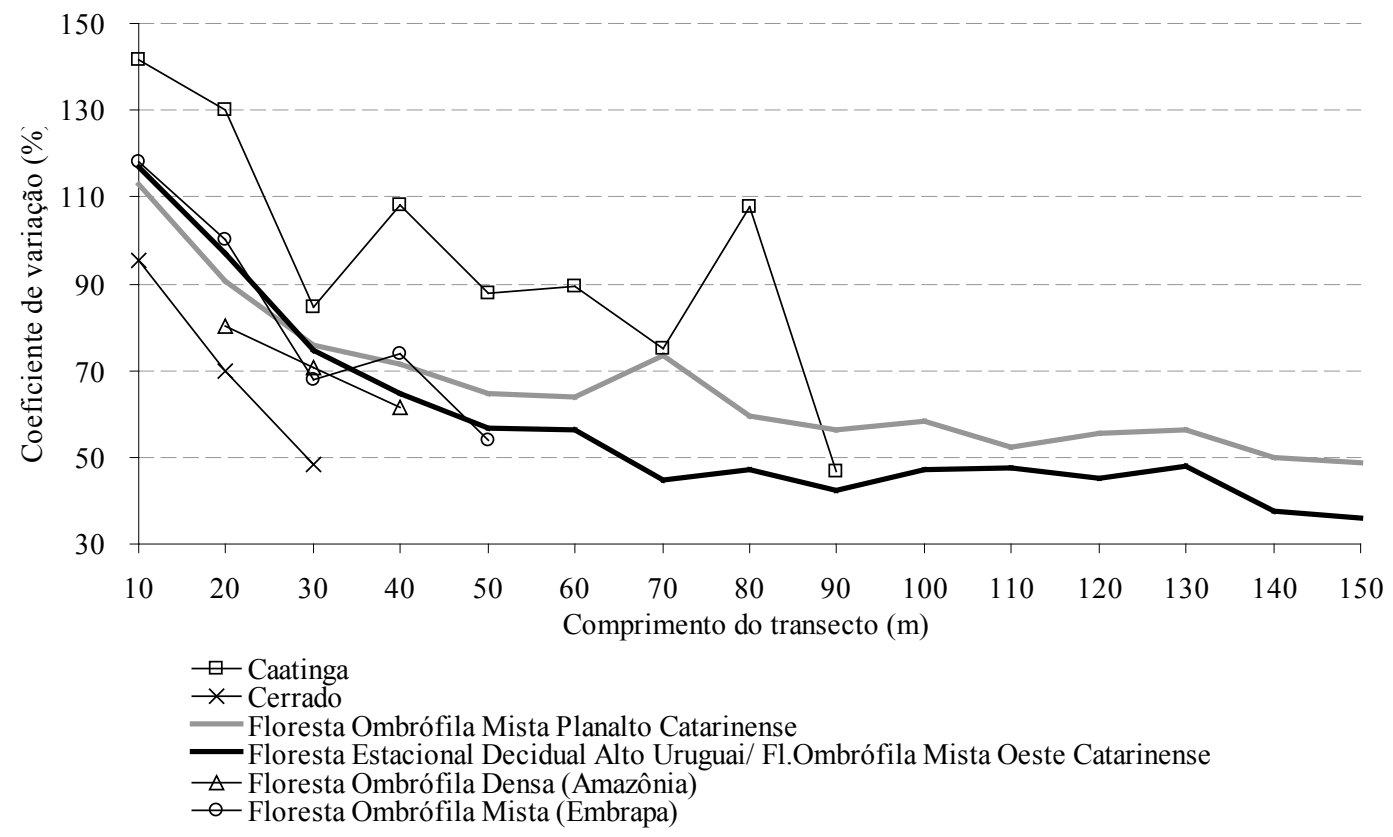

Figura 2. Coeficiente de variação para diferentes comprimentos de transecto e para diferentes tipologias de vegetação.

Woldendorp et al. (2004) testaram distribuição aleatória de transectos de 10, 20, 40, 60 e $80 \mathrm{~m}$ de comprimento e o resultado foi semelhante ao encontrado neste estudo, pois nas três áreas de floresta estudadas, o coeficiente de variação diminuiu à medida que o comprimento do transecto aumentou de $10 \mathrm{~m}$ até $80 \mathrm{~m}$, de $360 \%$ para $135 \%$ em uma das áreas, de $210 \%$ para $74 \%$ em outra e de $163 \%$ para $57 \%$ na terceira. Aredução foi maior para o aumento do comprimento de $10 \mathrm{~m}$ até $40 \mathrm{~m}$ e menor quando considerado de $40 \mathrm{~m}$ até $80 \mathrm{~m}$.

A intensidade amostral estimada para alcançar erro amostral de $15 \%$ e nível de confiança de $95 \%$ mostrou que, para a Floresta Estacional Decidual e Floresta Ombrófila Mista do oeste catarinense, seriam necessários 236 transectos de $10 \mathrm{~m}$, o que foi atendido nesse trabalho, onde foram considerados 264 transectos processados para essas tipologias (Tabela 2). No entanto, para chegar a $10 \%$ de erro amostral, seriam necessários 531 transectos para essas mesmas tipologias.

Na Floresta Ombrófila Mista do Planalto Catarinense, seria necessário medir mais 59 transectos de $10 \mathrm{~m}$, além dos 162 medidos, para alcançar um erro amostral de $15 \%$.

Especificamente para o bioma Caatinga, observa-se na Figura 2 que os transectos de $10 \mathrm{~m}$ e de $20 \mathrm{~m}$ apresentaram resultados semelhantes, e que a redução no coeficiente de variação de volume de necromassa ocorre para transectos de comprimento a partir de $30 \mathrm{~m}$. A adoção de transectos de $30 \mathrm{~m}$ neste bioma seria recomendável. Para a análise dos dados em conjunto, seriam necessários 152 transectos para conseguir $15 \%$ de erro amostral.

Nos testes realizados na Amazônia e no Cerrado havia poucas unidades amostrais, porém os resultados permitem observar que, tanto nestes biomas como nos demais, o número de transectos necessário para alcançar erro amostral de $15 \%$ é 2,25 vezes menor que o necessário para alcançar erro amostral de 10\%.

A intensidade amostral estimada para atingir erro amostral de $10 \%$ e de $15 \%$ decresce com o aumento do comprimento do transecto, atingindo valores quase constantes a partir do comprimento de $50 \mathrm{~m}$, especialmente para o erro amostral de 15\% (Figura 3).

A distância total a ser percorrida, que é o produto do comprimento do transecto pelo número de transectos medidos para alcançar um erro amostral de $15 \%$, seria entre $32 \%$ e $35 \%$ maior com transectos de $20 \mathrm{~m}$ se comparados aos de $10 \mathrm{~m}$, nos conjuntos de dados de Santa Catarina (Tabela 3). Resultado semelhante foi observado nos transectos instalados na Embrapa Florestas, em que a diferença seria de 55\% para o mesmo comparativo. Isto pode ser uma vantagem para os transectos de $10 \mathrm{~m}$, se considerados o custo e o tempo de caminhamento.Assim, utilizar transectos de 10 m pode ser vantajoso em termos de custo e tempo de caminhamento. Além disso, a adoção de um número maior de transectos (maior ou igual a 30) normalidade dos dados segundo o teorema central do limite (Werkema, 1996). 
Tabela 2. Intensidade amostral estimada para erro amostral de $10 \%$ e $15 \%$ e nível de confiança de $95 \%$ em comparação com o número de transectos medidos nos testes.

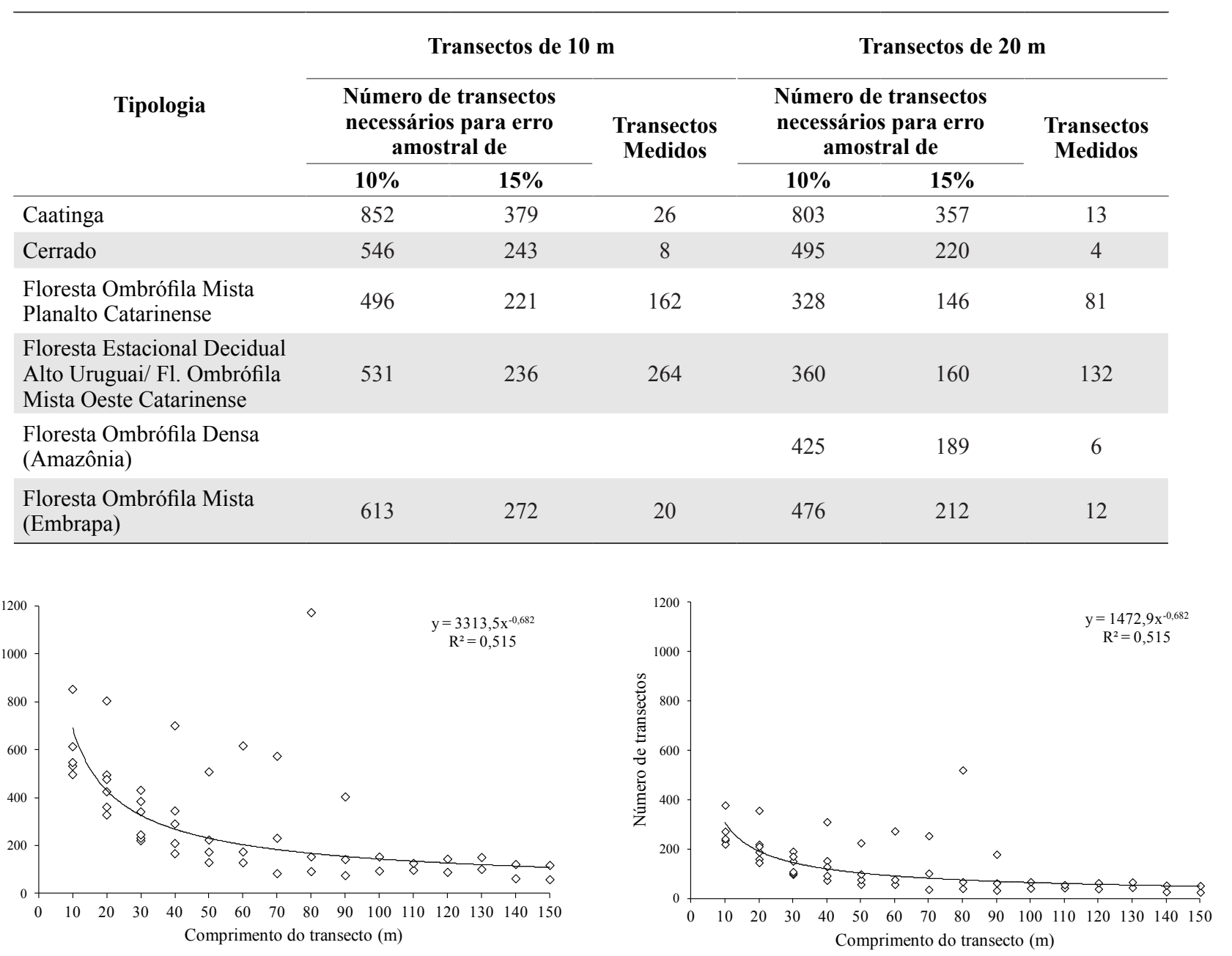

Figura 3. Simulação do número de transectos necessários para atingir erro amostral de $10 \%$ e de $15 \%$ em cada tipologia de vegetação.

Tabela 3. Distância a percorrer utilizando transectos de $10 \mathrm{~m}$ ou de $20 \mathrm{~m}$ para alcançar erro amostral de $15 \%$.

\begin{tabular}{cccc}
\hline & \multicolumn{3}{c}{ Distância a percorrer (m) } \\
\cline { 2 - 4 } $\begin{array}{c}\text { Comprimento do } \\
\text { Transecto }(\mathbf{m})\end{array}$ & $\begin{array}{c}\text { Floresta Estacional Decidual } \\
\text { Alto Uruguai/ Fl. Ombrófila } \\
\text { Mista Oeste Catarinense }\end{array}$ & $\begin{array}{c}\text { Floresta Ombrófila Mista } \\
\text { Planalto Catarinense }\end{array}$ & $\begin{array}{c}\text { Floresta Ombrófila Mista } \\
\text { Embrapa }\end{array}$ \\
\hline 10 & 2.362 & 2.205 & 2.723 \\
20 & 3.204 & 2.912 & 4.230 \\
\hline
\end{tabular}


À exceção dos dados de Santa Catarina, os demais conjuntos de dados são formados por material com diâmetro de até $20 \mathrm{~cm}$, o que resultou em percentuais de necromassa sobre o volume total das árvores, entre 1,2\% na Caatinga e $18,9 \%$ no Cerrado (Tabela 4 ).

Nas áreas de Santa Catarina, em que foi registrada a ocorrência de diâmetros superiores a $20 \mathrm{~cm}$, o percentual de necromassa observado foi de $13,7 \%$ e $20,8 \%$ (Tabela 4). Embora esta classe de diâmetro tenha sido desconsiderada na análise estatística e dos comparativos de comprimento de transecto, foi incluída nesta avaliação, pois representa entre $32 \%$ e $43 \%$ de necromassa medida, nos dois conjuntos de dados de Santa Catarina analisados.

O percentual referente ao somatório de necromassa caída e de volume de árvores mortas em pé em relação ao volume total variou entre $8,6 \%$ na Caatinga e $28,9 \%$ no Cerrado. Estes resultados são compatíveis com a afirmativa de Brown (2002), de que o volume total de necromassa incluindo árvores mortas em pé e fragmentos caídos no solo, com diâmetro superior a $10 \mathrm{~cm}$, pode representar $10 \%$ a $20 \%$ do volume de biomassa acima do solo.

Tabela 4. Representatividade do volume de necromassa em relação ao volume das árvores.

\begin{tabular}{|c|c|c|c|c|c|c|c|}
\hline \multirow{3}{*}{ Bioma } & \multicolumn{5}{|c|}{ Volume $\left(\mathrm{m}^{3} \mathrm{ha}^{-1}\right)$} & \multirow{3}{*}{$\begin{array}{l}\text { Necromassa } \\
\text { caída } \\
(\%)\end{array}$} & \multirow{3}{*}{$\begin{array}{c}\text { Necromassa caída } \\
+ \text { mortas em pé } \\
(\%)\end{array}$} \\
\hline & \multicolumn{2}{|c|}{ Necromassa caída } & \multicolumn{3}{|c|}{ Árvores* } & & \\
\hline & $\begin{array}{c}\text { diâmetro }< \\
20 \mathrm{~cm}\end{array}$ & $\begin{array}{l}\text { diâmetro }> \\
20 \mathrm{~cm}\end{array}$ & $\begin{array}{c}\text { Mortas } \\
\text { em pé }\end{array}$ & Vivas & $\begin{array}{c}\text { Árvores } \\
\text { Total }\end{array}$ & & \\
\hline Caatinga & 0,3 & & 1,9 & 23,3 & 25,2 & 1,2 & 8,6 \\
\hline Cerrado & 9,3 & & 4,9 & 34,9 & 39,8 & 18,9 & 28,9 \\
\hline $\begin{array}{l}\text { Floresta Ombrófila Mista } \\
\text { Planalto Catarinense }\end{array}$ & 21,6 & 16,3 & 5,0 & 139,6 & 144,6 & 20,8 & 23,5 \\
\hline $\begin{array}{l}\text { Floresta Estacional Decidual } \\
\text { Alto Uruguai/ Fl. Ombrófila } \\
\text { Mista Oeste Catarinense }\end{array}$ & 15,2 & 7,0 & 5,6 & 134,4 & 140,0 & 13,7 & 17,1 \\
\hline $\begin{array}{l}\text { Floresta Ombrófila Densa } \\
\text { (Amazônia)* }^{*}\end{array}$ & 29,5 & & 24,6 & 201,4 & 225,9 & 11,5 & 21,2 \\
\hline $\begin{array}{l}\text { Floresta Ombrófila Mista } \\
\text { (Embrapa) }\end{array}$ & 18,7 & & & 259,3 & 259,3 & 6,7 & 6,7 \\
\hline
\end{tabular}

*Volume de árvores estimado por equação ajustada por Rolim et al. (2006), para o bioma Amazônia, por Rezende et al. (2006) para o bioma Cerrado e por fator de forma nos demais conjuntos de dados.

O volume de necromassa obtido no bioma Amazônia, foi de 29,5 $\mathrm{m}^{3} \mathrm{ha}^{-1}$, considerando classes de diâmetro de $2 \mathrm{~cm}$ a $5 \mathrm{~cm}, 5 \mathrm{~cm}$ a $10 \mathrm{~cm}$ e maior que $10 \mathrm{~cm}$, sendo nesta última, verificado $49 \%$ do número de troncos e galhos analisados, porém sempre com diâmetro menor que $20 \mathrm{~cm}$. Esse resultado foi foi bem inferior ao obtido por Cruz Filho \& Silva (2009), que registraram $82 \mathrm{~m}^{3} \mathrm{ha}^{-1}$ em floresta não explorada e $137 \mathrm{~m}^{3} \mathrm{ha}^{-1}$ em floresta com exploração de impacto reduzido, para fragmentos de diâmetro superior a $10 \mathrm{~cm}$, com a mesma metodologia. $\mathrm{O}$ volume de necromassa para a Amazônia também foi inferior ao obtido por Palace et al. (2007), que para fragmentos com diâmetro maior que $2 \mathrm{~cm}$, registraram volume de $90,6 \mathrm{~m}^{3} \mathrm{ha}^{-1}$ e $121,1 \mathrm{~m}^{3} \mathrm{ha}^{-1}$ para floresta não explorada e para floresta com exploração de baixo impacto na Amazônia, respectivamente.

As diferenças nos resultados da Amazônia podem ser atribuídas ao diâmetro mínimo dos fragmentos estabelecido em cada um dos estudos, a diferenças de distribuição de frequência dos galhos e troncos por classe de diâmetro e especialmente, ao pequeno número de transectos avaliados (seis transectos de $20 \mathrm{~m}$ ). Além disso, o estoque de necromassa em florestas de terra firme na Amazônia é positivamente relacionado à dinâmica (mortalidade $\mathrm{e}$ taxa de decomposição, densidade média da madeira de árvores vivas) e à estrutura da floresta, como mencionado por Chao et al. (2009). 


\section{Conclusões}

A simulação para transectos de comprimentos de $10 \mathrm{~m}$ a $150 \mathrm{~m}$ sugere que transectos maiores que $50 \mathrm{~m}$ não contribuem muito para o aumento da precisão dos resultados.

A amplitude de variação de volume entre os transectos depende do limite mínimo de diâmetro de inclusão dos galhos e troncos.

Galhos e troncos caídos sobre o chão com diâmetro superior a $20 \mathrm{~cm}$ e que apresentam ocorrência esparsa ou heterogênea entre os transectos devem ser medidos, porém processados separadamente, em outro estrato, para não comprometer a precisão do resultado final da quantificação de necromassa.

A adoção do comprimento de $10 \mathrm{~m}$ pode ser vantajosa, pois embora exija maior número de transectos a medir e resulte em maior coeficiente de variação, se comparado ao obtido com transectos de $20 \mathrm{~m}$, permite menor distância total de caminhamento, para alcançar erro amostral de $15 \%$.

As respostas obtidas neste estudo devem ser refinadas com resultados quanto ao tempo e custo do trabalho de campo e avaliação do nível de decomposição dos fragmentos.

\section{Agradecimentos}

Os autores agradecem ao Dr. Carlos Alberto Ferreira, chefe da Unidade Regional Sul do Serviço Florestal Brasileiro pelas importantes sugestões para a análise dos dados e ao pesquisador Dr. André Biscaia de Lacerda da Embrapa Florestas, pelas indicações de referências bibliográficas que muito contribuíram para a construção do texto.

\section{Referências}

BAKER, T. R.; CHAO, K. J. Manual para medições de detritos de madeira grossa em parcelas RAINFOR. Leeds: Natural Environment Research Council, 2001. 10 p. Disponível em: $<$ http:// www.geog.leeds.ac.uk/projects/rainfor/pages/manuals_eng.html $>$. Acesso em: 09 nov. 2011.

BARBOSA, R. I.; SILVA, L. F. S. G. da; CAVALCANTE, C. de O. Protocolo necromassa: estoque e produção de liteira grossa. Boa Vista, RR: INPA, 2009. 24 p. Disponível em: <http://agroeco.inpa.gov. br/reinaldo/RIBarbosa_ProdCient_Usu_Visitantes/2009Barbosa $\% 20$ et $\% 20$ al_Protocolo\%20Necromassa_PPBio_Floresta.pdf $>$. Acesso em: 18 nov. 2011.

BÖHL, J.; BRÄNDLI, U. B. Deadwood volume assessment in the third Swiss National Forest Inventory: methods and first results. European Journal of Forest Research, Berlin, v. 126, n. 3, p. 449-457, 2007.
BRANTHOMME, A. Monitorização e avaliação de recursos florestais nacionais de angola: Inventário Florestal Nacional: guia de campo para recolha de dados: versão 2.2. Rome, 2009. 180 p. (National Forest Monitoring and Assessment Working Paper NFMA XX/P). Disponível em http://www.fao.org/forestry/23443-080f7ff16 8effbebedf09f3b1e2b80504.pdf. Acesso em 08 fev. 2012.

BROWN, S. Measuring carbon in forests: current status and future challenges. Environmental Pollution, Essex, n. 116, p. 363-372, 2002.

CANADIAN FOREST INVENTORY COMMITTEE. Canada's National Forest Inventory: ground sampling guidelines: version 5. [Ottawa], 2008. 271 p. Disponível em $<$ https://nfi.nfis.org/ documentation/ground_plot/Gp_guidelines_v5.0.pdf $>$. Acesso em: 23 nov. 2011

CHAO, K. J.; PHILLIPS, O. L.; BAKER, T. R.; PEACOCK, J.; LOPEZ-GONZALEZ, G.; VASQUEZ MARTINEZ, R.; MONTEAGUDO, A.; TORRES-LEZAMA, A. After trees die: quantities and determinants of necromass across Amazonia. Biogeosciences, Göttingen, v. 6, p. 1615-1626, 2009.

CRUZ FILHO, D.; SILVA, J. N. M. Avaliação da quantidade de resíduos lenhosos em floresta não explorada e explorada com técnicas de redução de impactos, utilizando amostragem por linha interceptadora, no Médio Mojú, Amazônia Oriental, Brasil. Acta Amazônica, Manaus, v. 39, n. 3, p. 527-532, 2009.

GALVÃO FILHO, A. F. Avaliação da aplicabilidade do método de amostragem por linhas interceptadoras na quantificação de resíduos de exploração florestal nas condições de uma floresta de Terra Firme na Amazônia Brasileira. 2010. 82 f. Dissertação (Mestrado em Ciências Florestais) - Universidade Federal Rural da Amazônia, Belém.

MCKENZIE, N.; RYAN, P.; FOGARTY, P.; WOOD, J. Sampling, measurement and analytical protocols for carbon estimation in soil, litter and coarse woody debris. Canberra: Australian Greenhouse Office, 2000. 52 p. (National Carbon Accounting System, Technical Report, 14). Disponível em: <http://pandora.nla.gov.au/pan/102841/200907 28-0000/www.climatechange.gov.au/ncas/reports/tr14final.html $>$. Acesso em: 24 nov. 2011.

PALACE, M.; KELLER, M.; ASNER, G. P.; SILVA, J. N. M.; PASSOS, C. Necromass in undisturbed and logged forests in the Brazilian Amazon. Forest Ecology and Management, Amsterdam, v. 238, p. 309-318, 2007.

PÉLLICO NETO, S.; BRENA, D. A. Inventário florestal. Curitiba, 1997. $136 \mathrm{p}$.

REZENDE, A. V.; VALE, A. T. do; SANQUETTA, C. R.; FIGUEIREDO FILHO, A.; FELFILI, J. M. Comparação de modelos matemáticos para estimativa do volume, biomassa e estoque de carbono da vegetação lenhosa de um cerrado sensu stricto em Brasília, DF. Scientia Forestalis, Piracicaba, n. 71, p. 65-76, 2006.

ROLIM, S. G.; COUTO, H. T. Z. do; JESUS, R. M. de; FRANÇA, J. T. Modelos volumétricos para a Floresta Nacional do TapirapéAquirí, Serra dos Carajás (PA). Acta Amazônica, Manaus, v. 36, n. 1, p. 107-114, 2006.

SERVIÇO FLORESTAL BRASILEIRO. IFN BR: formulário F5: medição de necromassa e serrapilheira. Disponível em <http://ifn.florestal.gov.br/images/stories/Link_ Documentos/f_5.pdf $>$. Acesso em: 26 abr. 2012. 
USDA FOREST SERVICE. Phase 3 field guide: down woody materials: version 5.1. 2011. Disponível em: $<$ http://fia.fs.fed. us/library/field-guides-methods-proc/docs/2012/field_gu ide_p3_5-1_sec25_10_2011.pdf $>$. Acesso em: 23 nov. 2011.

VAN WAGNER, C. E. Practical aspects of the line intersect method. Chalk River: Canadian Forestry Service, 1982. 18 p. (Information Report PI-X-12).

VAN WAGNER, C. E. The line intersect method in forest fuel sampling. Forest Science, Washington, DC, n. 14, p. 20-26, 1968.
VIBRANS, A. C.; SEVGNANI, L.; LINGNER, D. V.; GASPER, A. L. de; SABBAGH, S. Inventário florístico florestal de Santa Catarina (IFFSC): aspectos metodológicos e operacionais. Pesquisa Florestal Brasileira, v. 30, n. 64, p. 291-302, 2010. DOI: 10.4336/2010.pfb.64.291

WERKEMA, M. C. C. Como estabelecer conclusões com confiança: entendendo inferência estatística. Belo Horizonte: Fundação Christiano Ottoni, Escola de Engenharia da UFMG, 1996. 279 p. v. 4.

WOLDENDORP, G.; KEENAN, R. J.; BARRY, S.; SPENCER, R. D. Analysis of sampling methods for coarse woody debris. Forest Ecology and Management, Amsterdam, v. 198, p. 133-148, 2004. s 
